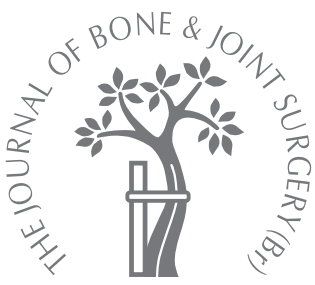

- ANNOTATION

\title{
The inadequacy of musculoskeletal knowledge after foundation training in the United Kingdom
}

S. S. Al-Nammari,
B. K. James,
M. Ramachandran

From Barts and The

London NHS Trust,

London, England
- S. S. Al-Nammari, MBChB, MRCSEd, Specialist Registrar M. Ramachandran, FRCS(Orth), Consultant Orthopaedic Surgeon Department of Trauma \& Orthopaedics

2nd Floor, John Harrison House, The Royal London Hospital, Whitechapel Road, London E1 1BB, UK.

B. K. James, MBChB, Foundation Doctor Ulster Hospital, Upper Newtownards Road, Dundonald, Belfast, BT16 1 RH Northern Ireland.

Correspondence should be sent to Mr M. Ramachandran; e-mail: manoj.ramachandran@ bartsandthelondon.nhs.uk

(C)2009 British Editorial Society of Bone and Joint Surgery doi:10.1302/0301-620X.91B11. $22445 \$ 2.00$

$J$ Bone Joint Surg $[\mathrm{Br}]$ 2009;91-B:1413-18.

The aim of this study was to determine whether the foundation programme for junior doctors, implemented across the United Kingdom in 2005, provides adequate training in musculoskeletal medicine. We recruited 112 doctors on completion of their foundation programme and assessed them using the Freedman and Bernstein musculoskeletal examination tool. Only $8.9 \%$ passed the assessment. Those with exposure to orthopaedics, with a career interest in orthopaedics, and who felt that they had gained adequate exposure to musculoskeletal medicine obtained significantly higher scores. Those interested in general practice as a career obtained significantly lower scores. Only $15 \%$ had any exposure to orthopaedics during the foundation programme and only $13 \%$ felt they had adequate exposure to musculoskeletal medicine. The foundation programme currently provides inadequate training in musculoskeletal medicine. The quality and quantity of exposure to musculoskeletal medicine during the foundation programme must be improved.

The foundation programme for junior doctors was implemented across the United Kingdom in August 2005. It consists of a mandatory twoyear period of postgraduate training for all United Kingdom medical school graduates and is typically made up of six four-month placements in various specialties. It is said to be designed to 'bridge the gap between medical school and specialty/general practice training. ${ }^{1}$ Structured and supervised training should be received throughout the programme, and trainees are assessed against standards set out in a formal foundation programme curriculum. The aim is to ensure that all junior doctors are 'equipped with the skills, attitudes and aptitudes that all doctors must possess for a career in the National Health Service'. ${ }^{1}$ The General Medical Council has overall responsibility for education during the first year of foundation training. The Postgraduate Medical Education and Training Board then becomes responsible for setting the standards of training for the second foundation year. On successful completion of the programme, the junior doctor starts specialist training and is unlikely to have further exposure to musculoskeletal medicine.

It has previously been reported that confidence and competence in musculoskeletal medicine is poor in medical school graduates, ${ }^{2-6}$ general practitioners ${ }^{7}$ and doctors in specialist training. ${ }^{8}$ To date, musculoskeletal medicine has not received adequate attention in the
United Kingdom undergraduate curriculum. ${ }^{9,10}$ The average length of time spent in orthopaedics in United Kingdom medical schools is five weeks, ${ }^{9}$ much of which is combined with training in other specialties, thereby reducing the length of orthopaedic attachments to an average of 2.7 weeks and accounting for only $2 \%$ of the available time in the clinical years of undergraduate training (years 3 to 5). ${ }^{9}$ Unfortunately, postgraduate training in the United Kingdom has a similar lack of focus on musculoskeletal medicine. For example, only $0 \%$ to $10.5 \%$ of vocational training schemes (general practitioner training schemes) in the North of England include orthopaedics or rheumatology. ${ }^{9,11}$

This gives cause for concern, as musculoskeletal complaints are the most common reason for patients seeking medical attention. ${ }^{12,13}$ They account for $23 \%$ to $27.8 \%$ of primary care $^{14,15}$ and approximately $20 \%$ of accident and emergency attendances. ${ }^{16}$ As the Bone and Joint Decade nears its end, ${ }^{17}$ it is imperative to recognise that experience in the basics of musculoskeletal medicine is essential for a variety of clinicians delivering care, including general practitioners and emergency physicians, as well as rheumatologists and orthopaedic surgeons. In order to investigate the scale of the problem we carried out a study to assess the musculoskeletal knowledge of junior doctors in the United Kingdom at the end of their foundation programme. 


\section{Subjects and Methods}

We enrolled junior doctors in the last two months of their two-year United Kingdom foundation programme (August 2006 to July 2008) and invited them to complete the Freedman and Bernstein musculoskeletal examination (Table I). ${ }^{4}$ Data about relevant demographic features, exposure to orthopaedics in the foundation programme and future specialist interest were collected. Verbal informed consent was obtained before the questionnaire was administered. All participants took part voluntarily. The examination was scored anonymously after data collection, which was performed between June and July 2008.

Of 140 people who were approached, 120 (86\%) agreed to take part. A total of 120 questionnaires were collected but only 112 were complete and therefore included in the study. There were 43 men and 69 women, of whom $15 \%$ (17 of 112) had gained some exposure to orthopaedics during their foundation programme; $6 \%$ (7 of 112) intended to pursue a career in orthopaedics and 36\% (40 of 112) a career in general practice. No individual specified an interest in rheumatology.

The Freedman and Bernstein musculoskeletal examination was developed to test how well medical school graduates understood basic musculoskeletal problems. ${ }^{4}$ It was produced and later validated by those chairing residency programmes in both orthopaedics ${ }^{4}$ and internal medicine. ${ }^{18}$ The pass mark was set at $73.1 \%$ by the orthopaedic surgeons and $70 \%$ by the physicians. The examination consists of 25 short-answer questions and is scored on a scale of 0 to 100 (Table I). In our study, the overall unweighted score was calculated as described in the original paper and the recommended pass mark set at $73.1 \%$. Each question was worth a maximum of 1 point. In order to obtain a score from 0 to 100 , raw scores were multiplied by four.

Statistical analysis. Statistical differences between groups of subjects were analysed according to the type of outcome variable. Categorical data were analysed using Fisher's exact test. Continuous data were analysed using the independent sample $t$-test. The level of significance was set at $\mathrm{p}$ $=0.05$.

\section{Results}

Overall scores. The mean cognitive examination score was $53.2 \%$ (24\% to $92 \%$ ). Only $8.9 \%$ (10 of 112 ) gained a score of $\geq 73.1 \%$ and passed, giving a failure rate of $91.1 \%$ (102 of 112). Only $13 \%$ (15 of 112) felt that the foundation programme had provided them with adequate exposure to musculoskeletal medicine. The scores for individual components of the cognitive examination are shown in Table I.

Scores by trainees with foundation programme exposure to orthopaedics. A total of 15\% (17 of 112) had gained some exposure to orthopaedics during their foundation programme. The mean cognitive examination score for this group was significantly higher at $62 \%$ (33\% to $92 \%$ ) compared to a mean of $51.6 \%(24 \%$ to $78 \%)$ for the group with no orthopaedic exposure $(\mathrm{p}=0.005)$. The pass rate for the cognitive examination was $18 \%$ ( 3 of 17 ) for those with exposure to orthopaedics in the foundation programme and $7 \%$ (7 of 95) for those without. This difference was not, however, statistically significant $(\mathrm{p}=0.176)$.

The mean duration of orthopaedic exposure was 13 weeks for the group exposed to orthopaedics and two weeks for the group as a whole (2 to 16). Those who felt that they had gained adequate exposure to musculoskeletal medicine during their foundation programme had a significantly higher mean cognitive assessment score averaging $64 \%(39 \%$ to $92 \%)$ compared to $51.6 \%(24 \%$ to $90 \%)$ $(\mathrm{p}=0.0014)$ for those who professed inadequate exposure. Scores by future specialty interest. Orthopaedics, general medicine and general practice were the future specialty interests of $6 \%$ (7 of 112), 29\% (32 of 112) and 36\% (40 of 112), respectively. Those with an interest in orthopaedics had a significantly better mean cognitive examination score of $64.8 \%(37 \%$ to $90 \%)$, compared to $52.8 \%(24 \%$ to $92 \%)$ for those not interested in orthopaedics ( $\mathrm{p}=0.026)$. Those with an interest in orthopaedics also had a significantly higher pass rate, at $43 \%$ (3 of 7 ), compared to $7 \%$ ( 7 of 105$)(\mathrm{p}=0.015)$ in those without an interest.

The pass rates and mean cognitive examination scores were similar in those with a future interest in general medicine as a career, compared to those without an interest in general medicine (Table II). Those with a future interest in general practice had a significantly lower mean cognitive examination score of $48.4 \%$ (24\% to $72 \%)$, compared to a mean of $55.6 \%(27 \%$ to $92 \%)$ for those not interested in general practice $(\mathrm{p}=0.009)$. Similarly, those with a future interest in general practice had a significantly lower pass rate of $0 \%$ (0 of 40 ) versus 14\% (10 of 72) ( $\mathrm{p}=0.009)$ for those who stated no interest in general practice.

\section{Discussion}

Our survey reveals that most junior doctors who complete the new foundation programme fail to achieve a basic level of competence in musculoskeletal medicine. At the end of the two-year foundation programme, only $8.9 \%$ (10 of 112) of junior doctors passed the basic Freedman and Bernstein musculoskeletal cognitive assessment. Given the high prevalence of musculoskeletal conditions that are likely to be encountered by most specialist trainees, this gives cause for concern.

The candidates performed particularly badly in anatomybased questions, which accounted for three of the four most poorly answered questions $(11,19,20$ and 24 of the examination), with only $13 \%$ (14 of 112 ), $26 \%$ (29 of 112 ), $26 \%$ (29 of 112) and 27\% (30 of 112) answering the respective questions correctly. Candidates also had poor knowledge of 'red flag' signs and symptoms. Questions 4, 5, 6 and 7 looked at these types of cases and $63 \%$ (71 of 112), $18 \%$ (20 of 112), 26\% (29 of 112) and 88\% (98 of 112), respectively, answered them correctly. Although, superficially some of these figures seem acceptable, they show that, for 
Table I. Freedman and Bernstein questionnaire ${ }^{4}$

\begin{tabular}{ll} 
& Questions \\
\hline 1. & What common problem must all newborns be examined \\
& for?
\end{tabular}

2. What is a compartment syndrome?

$\begin{array}{ll}\text { Marking scheme } & \text { Grou } \\ \text { Congenital dislocation of the hip (CDH, dislocation, } \\ \text { subluxation also accepted): } 1 \text { point }\end{array}$

Group score Rank score

subluxation also accepted): 1 point

Increased pressure in a closed fascial space:

81

1 point

3. Acute septic arthritis of the knee may be differentiated from inflammatory arthritis by which laboratory test?

4. A patient dislocates his knee in a car accident. What structure(s) is/are at risk for injury and therefore must be evaluated?

5. A patient punches his companion in the face and sustains a fracture of the 5 th metacarpal and a $3 \mathrm{~mm}$ break in the skin over the fracture. What is the correct treatment, and why?

6. A patient comes to the office complaining of low back pain that wakes him up from sleep. What two diagnoses are you concerned about?

7. How is compartment syndrome treated?

Any analysis of fluid from aspiration (cell count, Gram 77 stain, culture): 1 point

Must mention popliteal artery: 1 point

71

8

Irrigation and debridement; risk of infection:

Tumour and infection: $1 / 2$ point each

Scaphoid fracture (carpal bone fracture also accepted): 96 1 point

Hip dislocation: 1 point

His left limb is in a position of flexion at the knee and the hip, with internal rotation and adduction of the hip. What is the most likely diagnosis?

10. What nerve is compressed in carpal tunnel syndrome?

Median nerve: 1 point

94

Dorsiflexion of the great toe (toe extensors also nerve root. How is motor function of the 5 th lumbar nerve root tested?

12. How is motor function of the median nerve tested in the hand?

Any median function (metacarpophalangeal finger flexion; thumb opposition, flexion, or abduction): 1 point

Ligament sprain and Salter-Harris I fracture (sprain, fracture also accepted): $1 / 2$ point each show only soft-tissue swelling. He is tender at the distal aspect of the fibula. What are 2 possible diagnoses?

14. A patient presents with new-onset low back pain. Under what conditions are plain radiographs indicated? Please name 5 (example: history of trauma).

Age > 50; neurological deficit; bowel or bladder changes; history of cancer, pregnancy, drug use, or steroid use; systemic symptoms (night pain, fever) paediatric population: $1 / 4$ point each, full credit for 4 correct responses

Common peroneal nerve (peroneal nerve also What structure is at risk for injury? accepted): 1 point see him on the same day, and he has a knee effusion. An aspiration shows frank blood. What are the three most common diagnoses?

17. What are the five most common sources of cancer metastatic Breast, prostate, lung, kidney, thyroid: $1 / 4$ point to bone?

each, full credit for 4 correct responses

Any two correct statements (i.e. inflammatory vs osteoarthrosis. degenerative, proximal interphalangeal joint $v s$ not detected with a bone scan? 
Table I. Freedman and Bernstein questionnaire ${ }^{4}$

\begin{tabular}{|c|c|c|c|c|}
\hline & Questions & Marking scheme & Group score & Rank score \\
\hline 20. & $\begin{array}{l}\text { What is the function of the normal anterior cruciate ligament } \\
\text { at the knee? }\end{array}$ & $\begin{array}{l}\text { To prevent anterior displacement of the tibia on the } \\
\text { femur: } 1 \text { point }\end{array}$ & 29 & 23 \\
\hline 21. & $\begin{array}{l}\text { What is the difference between osteoporosis and } \\
\text { osteomalacia? }\end{array}$ & $\begin{array}{l}\text { Osteoporosis: decreased bone density; osteomalacia; } \\
\text { decreased bone mineralisation (any true statement } \\
\text { about epidemiology, pathophysiology, e.g. estrogen } \\
\text { vs vitamin D, also accepted): } 1 \text { point }\end{array}$ & 41 & 20 \\
\hline 22. & $\begin{array}{l}\text { In elderly patients, displaced fractures of the femoral neck } \\
\text { are typically treated with joint replacement, whereas } \\
\text { fractures near the trochanter are treated with plates and } \\
\text { screws. Why? }\end{array}$ & $\begin{array}{l}\text { Blood supply to femoral head (avascular necrosis, } \\
\text { nonunion also accepted): } 1 \text { point }\end{array}$ & 69 & 9 \\
\hline 23. & $\begin{array}{l}\text { What muscle(s) is/are involved in lateral epicondylitis } \\
\text { (tennis elbow)? }\end{array}$ & $\begin{array}{l}\text { Wrist extensors (full credit for any wrist extensor - } \\
\text { extensor carpi radialis brevis, extensor carpi radialis } \\
\text { longus, extensor digitorum communis): } 1 \text { point }\end{array}$ & 28 & 24 \\
\hline 24. & $\begin{array}{l}\text { Rupture of the biceps at the elbow results in weakness of } \\
\text { both elbow flexion and }\end{array}$ & Supination: 1 point & 45 & 18 \\
\hline 25. & $\begin{array}{l}\text { What muscle(s) control(s) external rotation of the humerus } \\
\text { with the arm at the side? }\end{array}$ & $\begin{array}{l}\text { Infraspinatus or teres minor accepted (full credit for } \\
\text { rotator cuff): } 1 \text { point }\end{array}$ & 66 & 10 \\
\hline
\end{tabular}

Reproduced with permission from the Journal of Bone and Joint Surgery [Am]

example, $37 \%$ (41 of 112 ) might not actively seek out arterial injury in patients who have dislocated a knee, $82 \%(92$ of 112) might not correctly diagnose and treat an open fracture, $74 \%$ (83 of 112 ) would not consider both tumour and infection in someone with low back pain which was waking them from sleep, and $13 \%$ (14 of 112) do not know that the treatment of compartment syndrome is surgical. Interestingly, candidates performed better in cases that might be considered medicolegal minefields, with question 1 about developmental dysplasia of the hip and question 8 about scaphoid fractures being answered correctly by $96 \%$ (108 of 112 ) and $86 \%$ (96 of 112), respectively.

There are several limitations to this study. Perhaps most importantly, our findings were limited by the validity of the Freedman and Bernstein questionnaire. This has many weaknesses, but is the only validated assessment tool for musculoskeletal medicine currently available. The original authors of the questionnaire accept its weaknesses and acknowledge that its validity may be limited by "the distribution of the topics, the open response format, the wording of the questions, and the accepted answers". 4 They also admit that "it could be argued that primary-care physicians rather than academic orthopaedic surgeons would have been the best group to have validated the examination."4 The passing score of a perfect competence examination would be $100 \%$, as all the material covered would be necessary. The questionnaire is, however, still valid, as "the passing score was set below $100 \%$ to adjust for flaws in the examination, indicating that the passing score that was set by the chairpersons already accounted for problems with the examination." 4 From the outset of our study the pass mark of $\geq 73.1 \%$ established by 124 orthopaedic programme directors was chosen instead of that of $\geq 70 \%$ established by 240 internal medicine programme directors. $^{4,18}$ Our rationale for this was that no examination was available that had been validated by primary-care physicians, and we felt that, of the two groups, orthopaedic programme directors would be better positioned to validate a study on musculoskeletal medicine, just as internal medicine programme directors would be better positioned to validate a study on cardiovascular or respiratory medicine. Selecting the higher pass mark may have changed some of our findings. Our study was also limited because we were unable to recruit from the whole of the United Kingdom's foundation programme, which might have introduced sample bias.

It was not the aim of this study to attempt to define specific measures to ensure that candidates who are entering specialty training have been adequately trained in the basics of musculoskeletal medicine. It is clear, however, that a solid foundation of knowledge should be laid at medical school and built upon during postgraduate training. Unfortunately, it is also clear that this is not currently happening. In order to achieve this it will be necessary to make broadbased reforms to both the undergraduate and the postgraduate curricula. At undergraduate level we believe that medical schools need to concentrate their efforts in two main areas. Firstly, they need to devote more time, resources and effort to gross anatomy. Since the publication of 'Tomorrow's Doctors' by the General Medical Council in 1993, ${ }^{19}$ most United Kingdom medical school curricula have undergone major changes. Preclinical and clinical phases have been merged, and the core subjects of preclinical medicine, such as pathology and anatomy, have suffered considerably as a result. Many institutions have discontinued dissectionbased teaching. There is no accepted gold standard format for teaching anatomy, but there can be no doubt that a 
Table II. Results of the Bernstein and Freedman questionnaire survey

\begin{tabular}{|c|c|c|}
\hline & Mean (\%) & Significant (p-value) \\
\hline FP $^{*}$ exposure to orthopaedics & 15 & $\mathrm{~N} / \mathrm{A}^{\dagger}$ \\
\hline Confident in musculoskeletal medicine & 13 & N/A \\
\hline Interested in orthopaedics & 6 & $\mathrm{~N} / \mathrm{A}$ \\
\hline Interested in general medicine & 29 & N/A \\
\hline Interested in general practice & 36 & N/A \\
\hline \multicolumn{3}{|l|}{ Examination scores } \\
\hline Whole group & 53.2 & $\mathrm{~N} / \mathrm{A}$ \\
\hline FP exposure to orthopaedics vs no exposure & 62 vs 51.6 & Yes $(0.005)$ \\
\hline Career interest in orthopaedics vs no interest & 64.8 vs 52.8 & Yes $(0.026)$ \\
\hline Career interest in general medicine $v s$ no interest & 55.6 vs 52 & No $(0.23)$ \\
\hline Career interest in general practice $v s$ no interest & 48.4 vs 55.6 & Yes (0.009) \\
\hline \multicolumn{3}{|l|}{ Pass rate } \\
\hline Whole group & 8.9 & N/A \\
\hline FP exposure to orthopaedics vs no exposure & 18 vs 7 & No $(0.176)$ \\
\hline Career interest in orthopaedics vs no interest & 43 vs 7 & Yes (0.015) \\
\hline Career interest in general medicine $v s$ no interest & 12.5 vs 17.5 & No $(0.31)$ \\
\hline Career interest in general practice $v s$ no interest & 0 vs 14 & Yes (0.009) \\
\hline
\end{tabular}

reduction in the time devoted to a subject is ultimately detrimental. A thorough knowledge of anatomy is essential to safe practice in any medical specialty, and this must be addressed. It is important to note that three of the four most poorly answered questions in our questionnaire were anatomy based. Secondly, during clinical training, medical schools must ensure that there is more exposure to musculoskeletal medicine. It has been shown that the average duration of an undergraduate attachment in trauma and orthopaedics was only 2.7 weeks (1.5 to 6 ) in the United Kingdom in 1999. ${ }^{9}$ In the United States, efforts have already been made to increase both the quantity and the quality of musculoskeletal training at undergraduate level. ${ }^{20}$ At postgraduate level, our study showed that those candidates who gained exposure to orthopaedics had a significantly higher mean score than their counterparts, and were also more likely to pass, although the latter finding was not statistically significant. Unfortunately, only $15 \%$ (17 of 112 ) of candidates were exposed to orthopaedics at any point during their foundation programme. The mean amount of time spent in orthopaedics was 13 weeks (2 to 16). This correlation between increased knowledge of musculoskeletal medicine and duration of exposure to orthopaedics has previously been reported. ${ }^{21}$ Although time spent in orthopaedics improved outcome in our study, even this group performed poorly, indicating that both the quantity and the quality of orthopaedic exposure need to be increased. In a study of a novel six-week musculoskeletal medicine course for first-year undergraduates, which consisted of only 44 hours of lectures, 17 hours of tutorials and 28 hours of laboratory anatomy, the mean score on the Freedman and Bernstein cognitive assessment was $77.8 \%$, compared to $59.6 \%$ for a historical comparison group $(\mathrm{p}<0.05) .{ }^{19} \mathrm{We}$ believe a shorter, but similar programme could be used to train foundation programme doctors to a satisfactory level, or could even be instituted earlier at undergraduate level. Ideally, foundation year training could take into account the future subspecialty interests of the candidates and provide a musculoskeletal component to those interested in general practice and orthopaedics.

Unsurprisingly, in our study, those with a future interest in orthopaedics had significantly better mean cognitive examination scores and pass rates than those interested in other specialties. Junior doctors must now make decisions about their final career path at a much earlier stage than previously. Our findings lend some support to the view that foundation trainees will really only get out of the programme what they feel they need for their planned career path. However, orthopaedic surgeons currently provide only $6 \%$ of musculoskeletal care in many developed countries, most being provided by those in other specialties, especially general practice. ${ }^{22}$ It is therefore essential that trainees with an interest in other specialties, particularly general practice, become competent in musculoskeletal medicine. Foundation trainees with a future interest in general practice performed poorly in our study, with significantly lower mean scores and pass rates. This is of particular concern, as these trainees may not gain further exposure to musculoskeletal medicine, ${ }^{9,11}$ and yet a substantial portion of their practice is likely to be devoted to musculoskeletal medicine. ${ }^{12-15}$ Furthermore, with the increasing age of the general population, it is predicted that the prevalence of musculoskeletal pathology is likely to increase. $^{23,24}$

Based on the low examination scores and pass rates among foundation trainees in our study, the United Kingdom foundation programme currently provides inadequate training in musculoskeletal medicine. This has significant 
bearing on the knowledge and competence of both future specialty trainees in orthopaedics and non-specialists such as general practitioners. The quantity and quality of exposure to musculoskeletal medicine during the foundation programme need to be significantly improved.

No benefits in any form have been received or will be received from a commercial party related directly or indirectly to the subject of this article.

\section{References}

1. No authors listed. The Foundation Programme Curriculum http://www.foundationprogramme.nhs.uk/pages/home/key-documents (date last accessed 20 May 2009).

2. Connell KJ, Sinacore JM, Schmid FR, Chang RW, Perlman SG. Assessment of clinical competence of medical students by using standardized patients with musculoskeletal problems. Arthritis Rheum 1993;36:394-400.

3. Jones JK. An evaluation of medical school education in musculoskeletal medicine at the University of the West Indies, Barbados. West Indian Med J 2001;50:66-8.

4. Freedman KB, Bernstein J. The adequacy of medical school education in musculoskeletal medicine. J Bone Joint Surg [Am] 1998;80-A:1421-7.

5. Schmale GA. More evidence of educational inadequacies in musculoskeletal medicine. Clin Orthop 2005;437:251-9.

6. Matzkin E, Smith EL, Freccero D, Richardson AB. Adequacy of education in musculoskeletal medicine. J Bone Joint Surg [Am] 2005;87-A:310-14.

7. Sneiderman C. Orthopedic practice and training of family physicians: a survey of 302 North Carolina practitioners. J Fam Pract 1977;4:267-70.

8. Camp BW, Gitterman B, Headley R, Ball V. Pediatric residency as preparation for primary care practice. Arch Pediatr Adolesc Med 1997;151:78-83.

9. Williams JR. The teaching of trauma and orthopaedic surgery to the undergraduate in the United Kingdom. J Bone Joint Surg [Br] 2000;82-B:627-8.

10. Spielmann PM, Oliver CW. The carpal bones: a basic test of medical students' and junior doctors' knowledge of anatomy. Surgeon 2005;3:257-9.

11. Booth A, Wise DI. General practice training in musculoskeletal disorders. Br J Gen Pract 1990;40:390
12. Hing E, Cherry DK, Woodwell DA. National Ambulatory Medical Care Survey: 2004 summary. Adv Data 2006;374:1-33.

13. Yelin E, Herrendorf A, Trupin L, Sonneborn D. A national study of medical care expenditures for musculoskeletal conditions: the impact of health insurance and managed care. Arthritis Rheum 2001;44:1160-9

14. KahI LE. Musculoskeletal problems in the family practice setting: guidelines for curriculum design. J Rheumatol 1987;14:811-14.

15. Spitzer WO, Harth $\mathbf{M}$, Goldsmith $\mathbf{C H}$, et al. The arthritis complaint in primary care: prevalence, related disability and costs. J Rheumatol 1976;3:88-99.

16. De Lorenzo RA, Mayer D, Geehr EC. Analyzing clinical case distributions to improve an emergency medicine clerkship. Ann Emerg Med 1990;19:746-51.

17. No authors listed. Bone and Joint decades musculoskeletal portal. http:// www.boneandjointdecade.org (date last accessed 20 May 2009).

18. Freedman KB, Bernstein J. Educational deficiencies in musculoskeletal medicine. $J$ Bone Joint Surg [Am] 2002;84-A:604-8.

19. No authors listed. Tomorrow's Doctors. http://www.gmc-uk.org/education/undergraduate/undergraduate_policy/tomorrows doctors/tomorrows doctors_2009.asp (date last accessed 25 September 2009).

20. Bilderback K, Eggerstedt J, Sadasivan KK, et al. Design and implementation of a system-based course in musculoskeletal medicine for medical students. J Bone Joint Surg [Am] 2008;90-A:2292-300.

21. Lynch JR, Schmale GA, Schaad DC, Leopold SS. Important demographic variables impact the musculoskeletal knowledge and confidence of academic primary care physicians. J Bone Joint Surg [Am] 2006;88-A:1589-95.

22. Karpman RR. Musculoskeletal disease in the United States: who provides the care? Clin Orthop 2001;385:52-6

23. Murray CJL, Lopez AD, eds. The global burden of disease: a comprehensive assessment of mortality and disability from diseases, injuries, and risk factors in 1990 and projected to 2020. Cambridge: Harvard School of Public Health on behalf of the World Health Organization and the World Bank; distributed by Harvard University Press, 1996:4.

24. Helmick CG, Lawrence RC, Pollard RA, Lloyd E, Heyse SP. Arthritis and othe rheumatic conditions: who is affected now, who will be affected later? Arthritis Care Res 1995;8:203-11. 